\title{
Renal impairment in stroke; a retrospective comparison between ischaemic and haemorrhagic variants
}

\author{
Kamalesh Tagadur Nataraju', Sourab Hiremath², Anushree Balan Nambiar ${ }^{3}$, \\ Abhilash Kalgottaru Nagabhushan ${ }^{4}$, Lanson Brijesh Colaco ${ }^{5}$ \\ ${ }^{1}$ Associate Professor, ${ }^{3,4}$ Post-Graduate Trainee, ${ }^{5}$ House Surgeon, Department of General Medicine, KVG Medical \\ College, Sullia, D.K, Karnataka, India - 574327, ${ }^{2}$ Assistant Professor, Department of General Medicine, Subbaiah \\ Institute of Medical Sciences, Shivamogga, Karnataka, India - 577222
}

Background: Cerebrovascular accident (also known as stroke) is a leading cause of mortality and morbidity in India. Renal dysfunction may be associated with increased recurrence of stroke and poorer long-term outcomes. Aims and Objectives: a) To find the relationship between CKD and occurrence of acute stroke b) To estimate the incidence of AKI in patients admitted with acute ischemic and hemorrhagic stroke. Materials and Methods: This is a retrospective analysis of renal function in patients admitted in K.V.G. Medical College Hospital with the diagnosis of "Acute stroke." All patients admitted in Medical Intensive Care Unit (M-ICU) and general wards from $1^{\text {st }}$ November 2018 to $31^{\text {st }}$ March 2020 were included in the study. Results: In this study, we included 80 patients who were admitted with the diagnosis of acute stroke. Sixty-four patients $(80 \%)$ had ischemic stroke and remaining sixteen (20\%) had haemorrhagic stroke. Twenty-eight patients (35\%) had renal dysfunction. The distribution of different types of renal dysfunction among different types of stroke was statistically insignificant ( $p$ value $=0.529$ ). Incidence of acute kidney injury (AKI) in our study is $25 \% .12$ patients $(15 \%)$ were found to have chronic kidney disease (CKD). The prevalence of CKD varies from 20 to $35 \%$ in ischemic stroke and 20 to $46 \%$ in haemorrhagic stroke. Conclusion: Renal dysfunction occurs frequently in patients with stroke. There was a significant proportion of patients with renal dysfunction. However, further prospective cohort studies are needed to find out the effect of renal dysfunction on Access this article online

Website:

http://nepjol.info/index.php/AJMS DOI: 10.3126/ajms.v12i7.35104 E-ISSN: 2091-0576 P-ISSN: 2467-9100

Copyright (c) 2021 Asian Journal of Medical Sciences

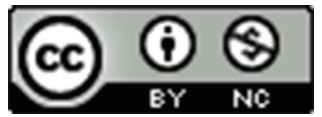

This work is licensed under a Creative Commons Attribution-NonCommercial 4.0 International License. stroke recovery and mortality.

Key words: Acute kidney injury; chronic kidney disease; stroke

\section{INTRODUCTION}

Cerebrovascular accident (also known as stroke) is a leading cause of mortality and morbidity in India. ${ }^{1}$ The estimated prevalence rate of stroke in rural and urban part of India ranges from, 84/100,000 - 262/100,000 and 334/100,000 - 424/100,000 respectively. ${ }^{1}$ According to recent population-based studies, the incidence rate is $119-145 / 100,000 .{ }^{1}$ Stroke accounted for $7 \%$ of medical and $45 \%$ of neurological admissions according to a stroke registry from Bangalore, with a fatality rate of $9 \%$ at hospital discharge and $20 \%$ at 28 days. $^{2}$ The leading aetiology is systemic hypertension which accounts to $54 \%$ of cases, followed by hypercholesterolemia $(15 \%)$ and then tobacco smoking $(12 \%) .^{3}$ Similarly, another stroke registry from Mumbai showed that $82.8 \%$ of patients had hypertension. ${ }^{4}$ This findings were further confirmed by similar findings in the stroke registry of Trivandrum, where nearly $85 \%$ had hypertension, $50 \%$ had diabetes mellitus, $26 \%$ had dyslipidaemia and $26.8 \%$ of men smoked tobacco. $^{5}$

Renal dysfunction is a common encounter in hospitalized patients. There is evidence of many hospitalized stroke 
patients who are not spared from concomitant renal dysfunction. ${ }^{6}$ Renal dysfunction may be associated with increased recurrence of stroke and poorer long-term outcomes. ${ }^{7}$ Between ischemic and haemorrhagic stroke, ischemic stroke is more frequently associated with acute renal dysfunction whereas nearly a third of patients with intracerebral haemorrhage $(\mathrm{ICH})$ have been noted to have chronic kidney disease (CKD). ${ }^{1,8}$ A reduced estimated glomerular filtration rate (eGFR) at admission after an acute ischemic stroke is associated with higher in-hospital mortality and prolonged hospital stay. ${ }^{9}$

CKD, defined by the presence of a reduced eGFR or the presence of albuminuria for greater than three months, is linked to increased incidence of stroke. ${ }^{9}$ The prevalence of $\mathrm{CKD}$ is estimated to be 8 to $16 \%$ worldwide. ${ }^{10} \mathrm{CKD}$ has been identified as an independent predictor of delayed recovery and mortality after an initial stroke. ${ }^{11,12}$ The reasons for poor clinical outcome of stroke in CKD is due to the presence of anaemia, chronic inflammation leading to oxidative stress, qualitative thrombocytopathy, electrolyte imbalance, uraemia, diabetes mellitus, hypertension, atrial fibrillation and hyperhomocysteinemia in such patients. ${ }^{13,14}$

Prevalence of $\mathrm{CKD}$ in patients with acute ischemic stroke varies from $20 \%$ to $35 \%{ }^{15,16}$ and in patients with acute intracerebral hemorrhage from $20 \%$ to $46 \% \cdot{ }^{17,4} \mathrm{CKD}$ with eGFR below $60 \mathrm{~mL} / \mathrm{min}$ per $1.73 \mathrm{~m}^{2}$ increases the risk of incident stroke by $43 \%$ with a further $7 \%$ increased risk for every $10 \mathrm{~mL} / \mathrm{min}$ per $1.73 \mathrm{~m}^{2}$ reduction. ${ }^{18,19}$

However, in addition to the above-mentioned facts, stroke can precipitate acute kidney injury (AKI) as well. This could be due to various factors such as - neurological deficit induced dysphagia leading to reduced oral fluid intake leading to pre-renal AKI, hemodynamic variations in blood pressure, cerebral salt wasting, thromboembolic events due to tissue-type plasminogen activator, as well as invasive investigations (contrast-induced nephropathy) and treatments (nephrotoxic drugs, mannitol used in case of raised intracranial tension in stroke). ${ }^{20,21}$ Occurrence of AKI following stroke varies widely with a range of $0.82 \%$ to $26.68 \%{ }^{20}$ and whereas it was $5.3 \%$ in a study conducted by Saeed $\mathrm{F}$ et al. ${ }^{21}$ This variation can be attributed to the different definitions of AKI employed by the authors.

\section{Need for the study}

Identifying the quantified risk of stroke in patients with CKD may help reduce its incidence and lead to a positive impact on their quality of life. Moreover, early identification and intervention of the renal derangement in stroke may reduce the mortality and morbidity significantly.
Estimated glomerular filtration rate (eGFR), a measure of renal function, is routinely assessed in patients with acute stroke at admission. There is insufficient knowledge on the trend of renal function in hospitalized stroke patients. Hence, this retrospective study was taken up to find the relationship between stroke and renal dysfunction.

\section{Aims and objectives}

1. To find the relationship between $\mathrm{CKD}$ and occurrence of acute stroke.

2. To estimate the incidence of AKI in patients admitted with acute ischemic and hemorrhagic stroke.

\section{MATERIALS AND METHODS}

This is a retrospective analysis of renal function in patients admitted in K.V.G. Medical College Hospital with the diagnosis of "Acute stroke." Both ischemic and hemorrhagic variants (based on brain imaging by computerized tomography or magnetic resonance imaging) were included. The study was approved by the institutional ethics committee. All patients admitted in Medical Intensive Care Unit (M-ICU) and general wards from $1^{\text {st }}$ November 2018 to $31^{\text {st }}$ March 2020 were included in the study.

The diagnosis of AKI was based on Kidney Disease: Improving Global Outcomes (KDIGO) criteria which is defined $^{22}-$ as presence as any one of the following;

1. Increase in serum creatinine $\geq 0.3 \mathrm{mg} / \mathrm{dL}$ $(\geq 26.5 \mu \mathrm{mol} / \mathrm{L})$ within 48 hours; or

2. Increase in serum creatinine $\geq 1.5$ times baseline, which is known or presumed to have occurred within the prior 7 days; or

3. Urine volume $<0.5 \mathrm{~mL} / \mathrm{kg} / \mathrm{h}$ for 6 hours.

We also included patients with biochemical evidence of pre-renal AKI on any day of hospitalization even in the presence of normal serum creatinine. Pre-renal AKI was defined as the ratio of blood urea nitrogen (BUN) to serum creatinine equal or more than 20:1. KDIGO criteria further categorizes AKI as stage 1, stage 2 and stage 3 based on serum creatinine and urine output. ${ }^{22}$ But, we did not categorize the patients into different stages as our objective was to find the occurrence of AKI and not staging or severity.

The diagnosis of CKD was based either on previously documented evidence, ultrasonographic imaging or ongoing maintenance renal replacement therapy.

\section{Inclusion criteria}

Patients aged more than 18 years who were admitted with the diagnosis of acute ischemic or acute hemorrhagic stroke. 


\section{Exclusion criteria}

1. Patients with incomplete or missing data.

2. Patients in whom the differentiation between AKI and CKD was not possible.

3. Identifiable causes of AKI like febrile illness, septicemia, septic shock, usage of nephrotoxic drugs.

\section{Sample size calculation}

- Calculated using the formula, $4 \mathrm{pq} / \mathrm{L}^{2}$

- Sample size was calculated using the formula, $4 p q / \mathrm{L}^{2}$. With $p$ set as 11 and allowable error as 7, minimum sample size was estimated to be 80 .

Type of study: Retrospective study

\section{Method of collection of data}

- The data was collected in a well-designed proforma.

- The parameters in the proforma are - age, gender, type of stroke, renal function tests (serum creatinine, blood urea, eGFR, routine urine examination) on day 1 and after 48 to 72 hours, blood pressure values at admission, 24 hours, 48 hours and at 72 hours, duration of hospital stay, complete blood count, plasma glucose levels (Random blood sugar (RBS) (if RBS is more than $200 \mathrm{mg} / \mathrm{dl}$ or if the patient is a known diabetic, Fasting blood sugar (FBS), Postprandial blood sugar (PPBS) and $\mathrm{HbA1c}$ were considered), renal ultrasound findings.

- eGFR was calculated using CKD-MDRD formula with variables including serum creatinine, age and gender. Readily available online calculators/mobile applications ("MDCalc" application) was used for the calculation.

All these data were tabulated into a spreadsheet software for analysis.

\section{Statistical analysis}

Patients were grouped into ischemic and hemorrhagic stroke groups. All the above data are compared between these two groups and the statistical significance were assessed using 'p' value. Proportion of stroke patients with pre-existing CKD and incidence of AKI in acute stroke was calculated by determining whether the patients had pre-existing renal dysfunction or the renal dysfunction started after the onset of stroke. Renal parameters were also compared with blood pressure at the time of admission and on subsequent 3 days to find the relationship between post stroke hypertension and AKI. In all those patients with pre-existing CKD, presence of comorbidities like diabetes mellitus, hypertension, blood hemoglobin levels and serum creatinine levels were analyzed for their relationship with the occurrence of stroke.

The data was entered in Microsoft office excel 2007 and SPSS version 21 was used for analysis. The data was shown in the form of percentages and means. Chi-square test \& $t$ test was used for analysis.

\section{RESULTS}

In this study, we included 80 patients who were admitted with the diagnosis of acute stroke. Sixty-four patients $(80 \%)$ had ischemic stroke and remaining sixteen $(20 \%)$ had haemorrhagic stroke. The demographic details of patients are shown in Table 1. Males and females constituted $61.25 \%$ and $38.75 \%$ of the sample respectively. The occurrence of ischemic stroke was more common in males (51.25\%) as compared to females $(28.75 \%)$. There was no variation in occurrence of haemorrhagic stroke between the sexes $(10 \%$ each.)

Twenty-eight patients (35\%) had renal dysfunction. Of these, twelve had evidence of CKD and twenty had evidence of AKI. Six patients had pre-existing diagnosis of CKD at admission. Remaining six patients were found to have CKD on admission based on ultrasonographic evidence with evidence of diabetic or hypertensive retinopathy). Among those with $\mathrm{CKD}, 4$ patients had AKI on already existing CKD. Hence, these patients were included under AKI category. Hence, among 20 patients with AKI, 4 were AKI on CKD. Ischaemic stroke was found to be associated with AKI and CKD more frequently than haemorrhagic type. However, the distribution of different types of renal dysfunction among different types of stroke was statistically insignificant $(\mathrm{p}$ value $=0.529)$ (Table 2).

All patient's data were collected for a period of 5 days of hospitalization to find out the day of occurrence and resolution of AKI. Patients who were discharged or who died before 5 days were also included for analysis. It was observed that 5 patients with AKI were either died or discharged before 5 days of hospitalization. Hence, resolution of AKI in these patients could not be known. AKI did not resolve in 2 patients even after 5 days of

\begin{tabular}{|c|c|c|c|}
\hline SI No. & Variables & Male & Female \\
\hline \multicolumn{4}{|c|}{ Age group } \\
\hline 1 & $31-40$ Years & $5(6.25 \%)$ & $0(0 \%)$ \\
\hline 2 & $41-50$ Years & $3(3.75 \%)$ & $2(2.5 \%)$ \\
\hline 3 & $51-60$ Years & $12(15 \%)$ & $2(2.5 \%)$ \\
\hline 4 & $61-70$ Years & $15(18.75 \%)$ & $12(15 \%)$ \\
\hline 5 & $71-80$ Years & $5(6.25 \%)$ & $10(12.5 \%)$ \\
\hline 6 & 81 - 90 Years & $8(10 \%)$ & $4(5 \%)$ \\
\hline 7 & $91-100$ Years & $1(1.25 \%)$ & $1(1.25 \%)$ \\
\hline \multicolumn{4}{|c|}{ Type of Stroke } \\
\hline 1 & Ischaemic & $41(51.25 \%)$ & $23(28.75 \%)$ \\
\hline 2 & Haemorrhagic & $8(10 \%)$ & $8(10 \%)$ \\
\hline
\end{tabular}


hospital stay. Resolution of AKI was observed in 12 patients (2 resolved on day 2, 5 resolved on day 3, 2 resolved on day 4 and 3 resolved on day5).

The blood levels of urea and serum levels of creatinine were compared with blood pressure over a period of 5 days (Figure 1 and 2 shows relationship between blood urea and serum creatinine on day 3). There was no statistically significant relationship between blood urea, serum creatinine and blood pressure.

\section{Table 2: Renal dysfunction in patients with stroke}

\begin{tabular}{lccc}
\hline Renal Disease & $\begin{array}{c}\text { Ischaemic } \\
\text { Stroke }\end{array}$ & $\begin{array}{c}\text { Haemorrhagic } \\
\text { Stroke }\end{array}$ & $\begin{array}{c}\text { Number of } \\
\text { patients }\end{array}$ \\
\hline $\begin{array}{l}\text { Acute Kidney } \\
\text { Injury }\end{array}$ & 12 & 4 & 16 \\
$\begin{array}{l}\text { Acute Kidney } \\
\text { Injury over }\end{array}$ & 4 & 0 & 4 \\
$\begin{array}{l}\text { Chronic Kidney } \\
\text { Disease } \\
\text { Chronic Kidney }\end{array}$ & 6 & 2 & 8 \\
Disease & & & \\
\hline
\end{tabular}

Chi-square value $=1.27$, $\mathrm{p}$ value $=0.529$
Proteinuria was observed in 35\% of patients with AKI. Most of these patients had proteinuria of grade 1 and 2 on urine dipstick method.

\section{DISCUSSION}

Incidence of $\mathrm{AKI}$ in our study is $25 \%$ (including 5\% of those with acute on chronic kidney disease). This is comparable to an incidence of $18 \%$ in a study conducted by Khatri $\mathrm{M}$ et al..$^{23}$ The incidence of AKI was even higher in another study on European subjects hospitalized with ischemic or haemorrhagic stroke..$^{24}$ In the same study the crude mortality after 1 month was much higher in those with AKI compared to those without (21.8\% vs $12.5 \%)$. Since ours was a retrospective study, we could not find the short term and long-term consequences of AKI on stroke related mortality and recovery.

Renal failure is not only limited to stroke but can occur in any patients admitted to intensive care units (ICU) for various reasons. In one study on patients admitted in ICU,

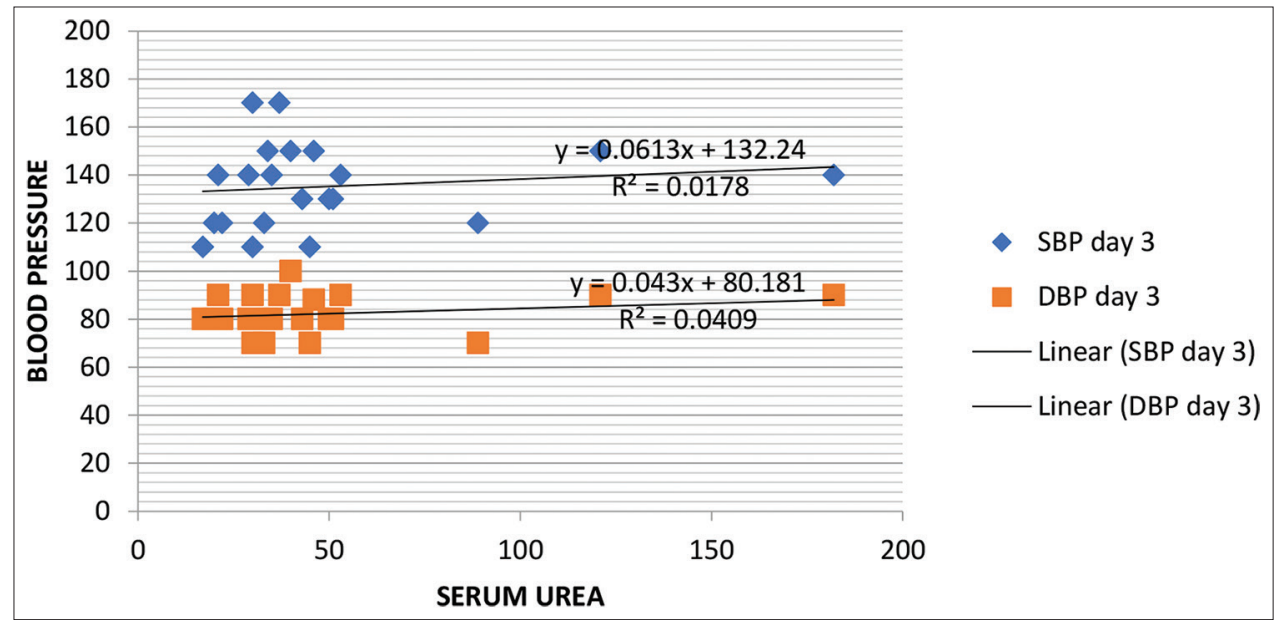

Figure 1: Relationship between blood urea and blood pressure on day 3

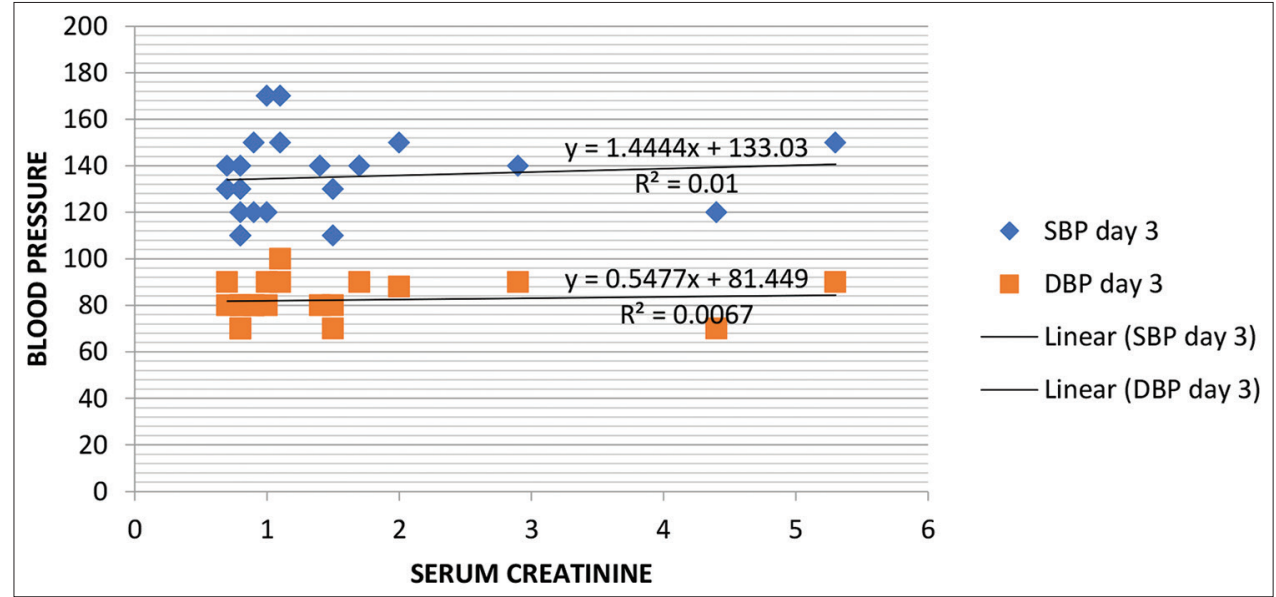

Figure 2: Relationship between serum creatinine and blood pressure on day 3 
the incidence of AKI was $5.7 \% .{ }^{25}$ In various studies on patients on sepsis admitted to ICU, the incidence of AKI varied from $9 \%$ to $51 \%{ }^{23,26}$ This variation is because of the variations in the definition of AKI used.

In our study, the proportion of ischemic stroke was $80 \%$ as compared to haemorrhagic stroke (20\%). The incidence of AKI was similar in ischemic stroke and haemorrhagic stroke (25\% in each group). However, study sample size is too small to comment on this finding. In the study done by Khatri $\mathrm{M}$ et al, the proportion of patients with intracerebral haemorrhage (ICH) was much higher which they attribute to the local referral bias and the expertise they had in their centre. They also found that the incidence of AKI was much higher in $\mathrm{ICH}$, probably due to use of mannitol and hypertonic saline.

The risk of developing AKI increases proportionately with the increasing severity of stroke. The occurrence of AKI after a stroke carries poor prognosis in the form of worse disability, prolonged hospital stays, increased in-hospital mortality, increased risk of future cardiovascular events and mortality. ${ }^{20,}{ }^{21}$ Khatri et al., ${ }^{22}$ has observed that AKI following ischemic stroke was related to greater mortality as compared to haemorrhagic stroke. The reasons for the higher rate of mortality are mostly due to co-existing conditions like myocardial infarction, atrial fibrillation, aspiration pneumonia, urinary tract infection, sepsis, accelerated hypertension, diabetic ketoacidosis, deep vein thrombosis, pulmonary thromboembolism and mechanical ventilation etc. ${ }^{21}$ AKI may directly worsen neuronal ischemic injury through further neuronal inflammation. ${ }^{27}$

In our study, 12 patients (15\%) were found to have CKD among whom 4 patients had acute on CKD. The prevalence of CKD varies from 20 to $35 \%$ in ischemic stroke and 20 to $46 \%$ in haemorrhagic stroke. ${ }^{15,16,17}$ In a study done on 6685 patients, CKD was found to be associated with 1.54 fold increased risk of incident stroke. ${ }^{28}$ The possible mechanisms of ischemic stroke in CKD include chronic inflammation and systemic hypertension leading to accelerated atherosclerosis and also concurrent ischemic heart disease with mural thrombus leading to cardioembolic stroke. ${ }^{29}$ Also, qualitative dysfunction of platelets due to uraemia and use of heparin for haemodialysis may increase the risk of haemorrhagic stroke.

Proteinuria is associated with $70 \%$ increased risk of incident stroke. ${ }^{30}$ This increased risk is attributable to "Steno hypothesis". ${ }^{31}$ However, we could not quantify proteinuria and compare it with the prognosis as it is a retrospective study. There was no statistically significant relationship between serial serum creatinine and urea levels with the daily blood pressure changes in our study.

\section{Limitations of the study}

1. We did not assess the severity of stroke which would have been helpful to understanding the relationship between the severity of stroke and the severity of renal dysfunction.

2. We did not compare the renal dysfunction with mortality in stroke patients.

3. Larger study sample size would have been statistically significant.

4. Long term follow up was not possible which would have shown the effect of renal dysfunction on stroke recovery.

\section{Strength of the study}

In this study, we tried to find the occurrence of stroke in $\mathrm{CKD}$ as well as occurrence of new renal dysfunction (AKI) or worsening of previously existing CKD (AKI on CKD) following ischaemic and haemorrhagic stroke.

\section{Take home message}

Since renal dysfunction is common in stroke, every treating physician should consider prevention, early recognition and early intervention of AKI in patients admitted with stroke for better prognosis and reduction of post stroke mortality.

The occurrence of AKI can be avoided by following these simple measures:

1. Recognizing patients inability to take oral liquids due to neurogenic dysphagia and providing adequate fluid resuscitation.

2. Strict monitoring of blood pressure and not allowing extreme variations in the blood pressures which can lead to hemodynamic stress on the kidney.

3. Avoiding nephrotoxic drugs.

4. Adequate measures to prevent deep vein thrombosis in the paralysed limb.

5. Early recognition of hyponatremia which may be due to cerebral salt wasting syndrome (CSWS).

Similarly, the risk of occurrence of stroke in CKD can be reduced by following measures:

1. Achieving blood pressure target.

2. Adequate measures to prevent accelerated atherosclerosis.

3. Addressing comorbid conditions like anaemia, hyperhomocysteinemia, and atrial fibrillation.

4. Avoiding use of heparin in patients with uremia induced qualitative thrombocytopathy.

\section{CONCLUSION}

Renal dysfunction occurs frequently in patients with stroke. There was a significant proportion of patients with renal dysfunction. However, further prospective cohort studies 
are needed to find out the effect of renal dysfunction on stroke recovery and mortality.

\section{ACKNOWLEDGEMENT}

The authors acknowledge the support of head of the department of General Medicine (Dr C Ramachandra Bhat).

\section{REFERENCES}

1. Jeyaraj $P$ and Paulin S. Stroke Epidemiology and Stroke Care Services in India. J Stroke. 2013; 15(3):128-134. https://doi.org/10.5853/10.5853/jos.2013.15.3.128

2. Nagaraja D, Gururaj G, Girish N, Panda S, Roy AK, Sarma GR, et al. Feasibility study of stroke surveillance: Data from Bangalore, India. Indian J Med Res. 2009; 130:396-403.

3. Strong K, Mathers C and Bonita R. Preventing stroke: Saving lives around the world. Lancet Neurol. 2007; 6:182-187. https://doi.org/10.5853/10.1016/S1474-4422(07)70031-5

4. Dalal PM, Malik S, Bhattacharjee M, Trivedi ND, Vairale J, Bhat P, et al. Population-based stroke survey in Mumbai, India: Incidence and 28-day case fatality. Neuroepidemiology. 2008; 3:254-261.

https://doi.org/10.5853/10.1159/000165364

5. Sridharan SE, Unnikrishnan JP, Sukumaran S, Sylaja PN, Nayak SD, Sarma PS, et al. Incidence, types, risk factors, and outcome of stroke in a developing country: The Trivandrum Stroke Registry. Stroke. 2009; 40:1212-1218.

https://doi.org/10.5853/10.1161/STROKEAHA.108.531293

6. Shrestha P, Thapa S, Shrestha S, Lohani S, BK S, MacCormac $\mathrm{O}$, et al. Renal impairment in stroke patients: A comparison between the haemorrhagic and ischemic variants. version 2 . F1000Research. 2017; 6:1531.

https://doi.org/10.5853/10.12688/f1000research.12117.2

7. El Husseini N, Fonarow GC, Smith EE, Ju C, Sheng S, Schwamm LH, et al. Association of kidney function with 30-day and 1-year poststroke mortality and hospital readmission: Get with The Guidelines-stroke. Stroke. 2018; 49:2896-2903.

https://doi.org/10.5853/10.5853/10.1161/STROKEAHA.118. 022011

8. Ovbiagele B, Schwamm LH, Smith EE, Grau-Sepulveda MV, Saver JL, Bhatt DL, et al. Hospitalized hemorrhagic stroke patients with renal insufficiency: clinical characteristics, care patterns, and outcomes. J Stroke Cerebrovasc Dis. 2014; 23(9): 2265-2273.

https://doi.org/10.5853/10.1016/j.jstrokecerebrovasdis.2014.04.016

9. Muntner P, Judd SE, McClellan W, Meschia JF, Warnock DG and Howard VJ. Incidence of stroke symptoms among adults with chronic kidney disease: results from the REasons for Geographic and Racial Differences in Stroke (REGARDS) study. Nephrol Dial Transplant. 2012; 27:166-173.

https://doi.org/10.5853/10.1093/ndt/gfr218

10. Jha V, Garcia-Garcia G, Iseki K, Li Z, Naicker S, Plattner B, et al. Chronic kidney disease: global dimension and perspectives. Lancet. 2013;382(9888):260-272.

https://doi.org/10.5853/10.5853/10.1016/S0140-6736(13)60687-X

11. Yahalom G, Schwartz R, Schwammenthal $Y$, Merzeliak O, Toashi M, Orion D, et al. Chronic kidney disease and clinical outcome in patients with acute stroke. Stroke. 2009; 40(4): 1296-1303.
https://doi.org/10.5853/10.1161/STROKEAHA.108.520882

12. Kim HJ, Kim JK, Oh MS, Kim SG, Yu KH and Lee BC. A low baseline glomerular filtration rate predicts poor clinical outcome at 3 months after acute ischemic stroke. J Clin Neurol. 2015; 11(1): 73-79. https://doi.org/10.5853/10.3988/jcn.2015.11.1.73

13. Schiffrin EL, Lipman ML and Mann JF. Chronic kidney disease: effects on the cardiovascular system. Circulation. 2007; 116(1): 85-97.

https://doi.org/10.5853/10.1161/CIRCULATIONAHA.106.678342

14. Toyoda K and Ninomiya T. Stroke and cerebrovascular diseases in patients with chronic kidney disease. Lancet Neurol. 2014; 13: 823-833. https://doi.org/10.5853/10.1016/S1474-4422(14)70026-2

15. Ovbiagele B, Bath PM, Cotton D, Sha N, Diener HC and PRoFESS Investigators. Low glomerular filtration rate, recurrent stroke risk, and effect of renin-angiotensin system modulation. Stroke. 2013; 44:3223-3225

https://doi.org/10.5853/10.5853/10.1161/STROKEAHA.113.002463

16. Kumai Y, Kamouchi M, Hata J, Ago T, Kitayama J, Nakane H, et al. FSR Investigators. Proteinuria and clinical outcomes after ischemic stroke. Neurology. 2012; 78:1909-1915.

https://doi.org/10.5853/10.5853/10.1212/WNL.0b013e318259e110

17. Molshatzki N, Orion D, Tsabari R, Schwammenthal $\mathrm{Y}$, Merzeliak O, Toashi M, et al. Chronic kidney disease in patients with acute intracerebral hemorrhage: association with large hematoma volume and poor outcome. Cerebrovasc Dis. 2011; 31:271-277.

https://doi.org/10.5853/10.5853/10.1159/000322155

18. Lee M, Saver JL, Chang KH, Liao HW, Chang SC and Ovbiagele B. Low glomerular filtration rate and risk of stroke: Meta-analysis. BMJ. 2010; 341:c4249. https://doi.org/10.5853/10.5853/10.1136/bmj.c4249

19. Masson P, Webster AC, Hong M, Turner R, Lindley RI and Craig JC. Chronic kidney disease and the risk of stroke: a systematic review and meta-analysis. Nephrol Dial Transplant. 2015; 30:1162-1169. https://doi.org/10.5853/10.1093/ndt/gfv009

20. Arnold J, Ng KP, Sims D, Gill P, Cockwell P and Ferro C. Incidence and impact on outcomes of acute kidney injury after a stroke: a systematic review and meta-analysis. BMC Nephrol. 2018; 19: 283.

https://doi.org/10.5853/10.1186/s12882-018-1085-0

21. Saeed F, Adil MM, Khursheed F, Daimee UA, Branch LA, Vidal GA, et al. Acute renal failure is associated with higher death and disability in patients with acute ischemic stroke. Stroke. 2014; 45:1478-1480. https://doi.org/10.5853/10.1161/STROKEAHA.114.004672

22. Kidney Disease Improving Global Outcomes (KDIGO) Clinical Practice Guideline for Acute Kidney Injury. Kidney Int Suppl. 2012; 2:1-138.

23. Khatri M, Himmelfarb J, Adams D, Becker K, Longstreth WT and Tirschwell DL. Acute kidney injury is associated with increased hospital mortality after stroke. J Stroke Cerebrovasc Dis. $2014 ; 23: 25-30$. https://doi.org/10.5853/10.1016/j.jstrokecerebrovasdis.2012.06.005

24. Tsagalis G, Akrivos T, Alevizaki M, Manios E, Theodorakis M, Laggouranis A, et al. Long-term prognosis of acute kidney injury after first acute stroke. Clin J Am Soc Nephrol. 2009;4(3):616-622. https://doi.org/10.5853/10.2215/CJN.04110808

25. Uchino S, Kellum JA, Bellomo R, Doig GS, Morimatsu H, Morgera $\mathrm{S}$, et al. Beginning and Ending Supportive Therapy for the Kidney 
(BEST Kidney) Investigators. Acute renal failure in critically ill patients: a multinational, multicenter study. JAMA. 2005;294(7):813818.

$$
\text { https://doi.org/10.5853/10.1001/jama.294.7.813 }
$$

26. Rangel-Frausto MS, Pittet D, Costigan M, Hwang T, Davis CS and Wenzel RP. The natural history of the systemic inflammatory response syndrome (SIRS): a prospective study. JAMA. 1995; 273:117-123

https://doi.org/10.5853/10.1001/jama.1995.03520260039030

27. Liu M, Liang Y, Chigurupati S, Lathia JD, Pletnikov M, Sun Z, et al. Acute kidney injury leads to inflammation and functional changes in the brain. J Am Soc Nephrol. 2008; 19:1360-1370. https://doi.org/10.5853/10.1681/ASN.2007080901

28. Koren-Morag N, Goldbourt U and Tanne D. Renal dysfunction and risk of ischemic stroke or TIA in patients with cardiovascular disease. Neurology. 2006; 67:224-228.

https://doi.org/10.5853/10.1212/01.wnl.0000229099.62706.a3

29. Khella $S$ and Bleicher MB. Stroke and its prevention in chronic kidney disease. CJASN. 2007; 2(6):1343-1351. https://doi.org/10.5853/10.2215/CJN.04341206

30. Kelly $D$ and Rothwell PM. Disentangling the multiple links between renal dysfunction and cerebrovascular disease. Journal of Neurology, Neurosurgery \& Psychiatry. 2020; 91:88-97.

https://doi.org/10.5853/10.1136/jnnp-2019-320526

31. Deckert T, Feldt-Rasmussen B, Borch-Johnsen K, Jensen T and Kofoed-Enevoldsen A. Albuminuria reflects widespread vascular damage. The Steno hypothesis. Diabetologia.1989;32:219-226. https://doi.org/10.5853/10.1007/BF00285287

\section{Author's contribution:}

KTN- Concept and design of the study; prepared first draft of manuscript; SH- Interpreted the results; reviewed the literature and manuscript preparation;

ABN- Concept, coordination, review of literature and manuscript preparation; AKN- Concept, coordination, review of literature and manuscript preparation; LBCStatistically analysed and interpreted, preparation of manuscript and revision of the manuscript.

Work attributed to:

KVG Medical College, Kurunjibhag, Sullia, D.K, Karnataka, India.

\section{Orcid ID:}

Dr. Kamalesh Tagadur Nataraju- (10) https://orcid.org/0000-0003-3517-9752

Dr. Sourab Hiremath- (D https://orcid.org/0000-0001-6478-9678

Dr. Anushree Balan Nambiar- (1) https://orcid.org/0000-0003-2661-0264

Dr. Abhilash Kalgottaru Nagabhushan- (1) https://orcid.org/0000-0001-8580-1437

Dr. Lanson Brijesh Colaco- (i) https://orcid.org/0000-0001-9473-8185

Source of Funding: None, Conflict of interest: None. 